\title{
ONOMÁVEIN
}

Journal of linguistics, philology and translation

\section{'We kissed one another and parted good friends.' On the expression of reciprocity in Early Modern English ${ }^{1}$}

\author{
Javier Calle Martín \\ Universidad de Málaga \\ España
}

\section{(C) $(i)$}

Javier Calle Martín: Departamento de Filología Inglesa, Francesa y Alemana, Universidad de Málaga, España. | E-mail: jcalle@uma.es 


\section{Abstract}

Reciprocity in contemporary English is normally expressed by means of the compound pronouns each other and one another, both constructions used interchangeably and without any apparent difference in meaning, even though various factors have been proposed to account for the choice between the two alternatives. Among them, style stands out as the most convincing argument postulating the use of each other and one another in informal and formal contexts, respectively. In corpus-oriented grammars, their usage is explained in terms of register variation, each other being by far the most common form in all contexts while one another becomes relatively common in fiction and academic prose (Biber et al., 1999: 346-347).

From a historical viewpoint, each other stems from those Old English constructions in which the quantifier ælc occurs with the alterity word opper in neighbouring positions, while one another is a Late Middle English development of (the) one + (the) (an)other, where the first element is also the grammatical subject and the second the object (Haas, 2010: 63-68). Since then, both reciprocals have competed for more than five centuries for the expression of reciprocity in English and, interestingly enough, the dilemma is still unresolved, contradicting the general assumption that the competition between forms whose meaning is compatible is usually resolved either by the loss of one of them or by the adoption of a different (Kahlas-Tarkka, 2004: 132). The Early Modern English period becomes a crucial period in the history of reciprocals witnessing the transition from the discontinuous forms each the other and one the other to the fossilized constructions each other and one another. In the light of this, the present paper pursues the following objectives: a) to trace the origin, grammaticalization and univerbation of each other and one another within their own paradigm in Early Modern English, and b) to analyse the use and distribution of these reciprocals to determine the date and the circumstances that contributed to the adoption of each other over one another for the expression of reciprocity in the history of English. The source of evidence comes from the Early English Books Online Corpus (for the period 1473-1700) and the Old Bailey Corpus (for the period 1674-1913).

Keywords: each other; Early Modern English; grammaticalization; one another; reciprocals.

$1 \quad$ The present research has been funded by the Spanish Ministry of Economy (grant numbers FFI2014-57963P and FFI2017-88060-P). These grants are hereby gratefully acknowledged. I am also grateful to Prof. Javier Pérez-Guerra (University of Vigo) for his valuable help in the statistical analysis of the data. I also wish to thank the two anonymous referees of Onomázein, whose thoughtful comments have substantially improved the final version of this article. 


\section{Introduction}

In present-day English, reciprocity is normally expressed by means of the compound pronouns each other and one another for the expression of a two-way reflexive relationship. Unlike reflexive pronouns, reciprocals ${ }^{2}$ can only refer to plural noun phrases insofar as reciprocity implies more than one participant (Biber et al., 1999: 346; Dalrymple et al., 1998: 159-160).3 This type of relationship stems from the correlative use of each ... other and one ... another in sentences like they each love the other or they hugged one after another, these becoming the source of they love each other and they hugged one another, respectively (Quirk et al., 1985: 364). The acceptability of these reciprocals in present-day English has been extensively addressed in the literature in the sense that they "can only occur [...] as the head or modifier of the subject but more freely with other constituents, particularly with the predicative complement" (Kahlas-Tarkka, 2004: 124). More important are, however, the contexts in which they are avoided as they cannot function as genitival s-modifiers nor appear in combination with passive constructions and, like the reflexive pronouns, they do not generally take the subject position in finite clauses, even though non-finite verb clauses are generally impervious to this constraint ${ }^{4}$ (Kjellmer, 1982: 235; Kahlas-Tarkka, 2004: 123).

Today both constructions are frequently used interchangeably and without any apparent difference in meaning, although various factors have been proposed to participate in the choice of these alternative forms. On strictly prescriptive grounds, each other has been traditionally argued for reference to two, whilst one another has been reserved for reference to more than two, to such an extent that ignoring this rule was considered as 'improper English' (Ussher, 1775: 19; Gardiner, 1799: 80-81; Angus, 1800: 34). ${ }^{\text {T }}$ This prescriptive bias has been retained in some dictionaries and grammar books since the 18th century (Churchill, 1823: 77; Brown, 1851: 263-264; Sullivan, 1855: 52; Pink, 1928: 48; Partridge, 1947: 101), even though it has also

2 Even though they are referred to as 'reciprocal pronouns' or 'reciprocal anaphors' in many descriptive grammars, the term reciprocal is adopted for convenience in the present study. Following Haas, the term reciprocal is more appropriate because these forms do not have any inflectional variability and, in sharp contrast with other reciprocal pronouns, they belong to the type of 'bipartite quantifier NP' (Haas, 2007: 31-32).

3 The plurality of the construction cannot necessarily be overt as it can also be understood from the context (Kjellmer, 1982: 239; Kahlas-Tarkka, 2004: 124).

4 Despite this prescriptivist constraint, reciprocals in subject position are observed to be an early 20th-century adoption. In this vein, Bolinger states that it is "a construction that has become commonplace in the past half-century" as a result of a syntactic context expansion leading to the adoption not only of the subject position in finite clauses, but also in the position of prepositional or genitive complement (1990: 267; Haas 2007: 45-48).

5 Gardiner was the second grammarian proposing this rule because he copied many of her examples from George Neville Ussher's work (Cajka, 2008: 197). 
been seriously criticised on account of its doubtful historical justification in contemporary usage (Kruisinga, 1938; Erades, 1950; Potter, 1953; Gutschow, 1960; Fowler, 1968: 143; Todd and Hancock, 1986: 170; Greenbaum and Whitcut, 1988: 231). 19th-century prescriptivists, in turn, proposed to differentiate the reciprocals in terms of their limited and unlimited condition, each other applying to a limited number and one another referring to an unlimited number (Marsh, 1862: 122). ${ }^{6}$ Irrespective of the prescriptive postulate, the OED records that neither of these restrictions ever existed in English usage and "the interchangeability of each other and one another had been established centuries before T.O. Churchill (or whoever it was) thought up the rule" (Gilman, 1989: 378).7 Other prescriptivists went beyond these simple concord rules questioning the correctness of one another in favour of the alternative one from the other whenever it is accompanied by a preposition, arguing that in these cases the words are more easily separated by placing the preposition between them. In this vein, a statement such as these two towns are at a great distance one from the other is taken "by far a less inelegant, as well as a more proper and correct, way of speaking than these two towns are at a great distance from one another" (Baker, 1779: 88; also Staniford, 1800: 88).

From a semantic standpoint, on the other hand, the distinction between the two reciprocals is said to rely on the clear plurality of the antecedents and a perfect symmetry of the actions insofar as each other is favoured if the speaker considers the agents as individuals or single units and one another prompted with shared or mutual actions (Kjellmer, 1982: 250). Another semantic argument has been proposed in terms of the general or specific scope of the statement in such a way that one another is more likely to be used in general statements as in people should help one another whilst each other is more frequent with reference to particular people as in the children help each other (Beresford, 1997: 23). As in the previous cases, these rules are not void of exceptions suggesting that they were also postulated on unfounded premises.

Interestingly enough, there have been other reasons to explain the difference between these forms in English, albeit with the same level of success. Stuurman, for instance, proposes to evaluate them according to the following two variables. The first is semantically-oriented considering that, while each other expresses 'a chain relation', one another is the pronoun to convey 'a true reciprocal relation' (1987: 353-360). This view, however, has not been deprived of controversy and was soon challenged in the assumption that this rule "can hardly constitute anything like a general rule, but may, at the outside, be taken as a more or less noticeable

6 See, for instance, the limited number implied in the statement Moses went out to meet his fatherin-law, and did obeisance, and kissed him; and they asked each other of their welfare in opposition to the unlimited number in Greet ye one another with an [sic] holy kiss (Marsh, 1862: 122).

7 As far as I have been able to trace, this prescriptive prerogative was originally proposed by Ussher in The Elements of English Grammar (1775: 19) based on unfounded premises. 
tendency in the language" (Jørgensen, 1988: 355). The second is more of a phonological nature. A few years later, Stuurman turned his attention to the relative weight of the two compound pronouns, one having three and the other four syllables, a fact which can tentatively explain the relative frequency of each other if compared with the more constrained dimension of one another, the latter preferred when some kind of variety is intended (1989: 356-357).

Setting aside all these unsuccessful attempts to formally characterise the two variants, the only difference between each other and one another is purely stylistic in the sense that the former is today the more common variant whilst the latter is "the rarer and stylistically more elevated one" (Kjellmer, 1982: 253). In some corpus-oriented grammars, their difference has also been characterised as a result of register variation, each other being by far the most common form in all contexts and one another predominating in fiction and academic prose (Biber et al., 1999: 346-347).

Historically speaking, the origin of each other dates back to the Old English construction æelc +o oper, the former as the subject and the latter usually inflected in the accusative, genitive or dative case. One another, in turn, is a Late Middle English development of one + (to) another, where the first element is also the grammatical subject and the second the object (Haas, 2010: 63-68). Since then, both reciprocals have coexisted for the expression of the same function for more than five centuries in English and, as such, they can be considered as a typical example of linguistic forms in competition over time. Interestingly enough, the outcome is still unresolved after five centuries, thus contradicting the general assumption that the comptetition between forms whose meaning is compatible is usually resolved either by the loss of one competing form or by a change in which one of them adopts a different meaning (Kahlas-Tarkka, 2004: 132). The particular case at hand, however, does not allow us to propose a driving force differentiating the usage of these variants in present-day English, style standing out as the most convincing argument in favour of each other.

The topic has been extensively dealt with in the literature in the attempt to define the scope and usage of these reciprocals in present-day English portraying the differences between the two constructions, if any, with moderate levels of success. Historical corpus-based approaches, however, have not proliferated in the last decades, perhaps as a result of the constrained distribution of these reciprocals in historical corpus data. ${ }^{8}$ The compilation of larger corpora, especially in the last decade, has come to facilitate the inspection of low-frequency constructions, reciprocals among others. In the light of this, the present paper deals with the development of reciprocals in early English with the following objectives: a) to trace the origin, grammaticalization and univerbation of each other and one another within their own

8 Kahlas-Tarkka is the only corpus-based approach to these reciprocals in the light of the Helsinki Corpus of English Texts (2004). 
paradigm in Early Modern English, and b) to analyse the use and distribution of both reciprocals to determine the date and the circumstances that contributed to the adoption of each other over one another for the expression of reciprocity in the history of English.

\section{Methodology}

The source material comes from the Early English Books Online Corpus (EEBOC) and the Old Bailey Corpus $(O B C)$. These corpora have been chosen in the light of their quantitative and qualitative features as they provide a sizeable input for the analysis of linguistic constructions in the period, especially considering the low frequency of reciprocals after their inception in Late Middle English and Early Modern English. Their chronology and size turned them into the appropriate sources for the study of textual variation over time, providing accurate information about on-going changes in Modern English.

EEBOC, developed by Mark Davies at Brigham Young University, is a 400-million word corpus from the 30,000 volumes housed in Early English Books Online for the historical period 1470$1690 .{ }^{9}$ In strictly qualitative terms, in the line of other corpora compiled by Mark Davies, the corpus allows the user to investigate the development of a linguistic item in each of the 23 decades in which it is organised, becoming the ideal input for investigation of changes in meaning and usage from a diachronic perspective. ${ }^{10}$ This version of the corpus is also POStagged and facilitates introspection not only by lemma but also by part-of-speech by means of a user-friendly interface and an attractive presentation of the results, which becomes an added asset if compared with the standard EEBO interface, more limited in its scope.

The OBC compiles the Proceedings of the Old Bailey, London's central criminal court, with roughly 124 million words for the historical period $1674-1913 .{ }^{11}$ This material comes from the annotations taken down in shorthand by the scribes in the courtroom and, consequently, it stands out as a close reproduction of the spoken word of the period. Apart from the pragmatic and textual information of the samples, the corpus is also provided with socio-biographical information about speakers, including features such as gender, age, occupation and social class.

9 Early English Books Online (EEBO) is a collaborative project "launched in 1999 by the University of Michigan, Oxford University Press and ProQuest Information and Learning to create a full-text archive of Early English" (Xiao, 2008: 404).

10 For a more detailed description of the corpus potential, see the Mark Davies' account in the corpus webpage (http://corpus.byu.edu/eebo/).

11 For a comprehensive description of the corpus potential, visit the corpus homepage (http://www1. uni-giessen.de/oldbaileycorpus/index.html). 
Mark Davies' tagged version of EEBOC has been designed using the CLAWS 7 POS-tagger. ${ }^{12}$ In this particular case, the instances were automatically retrieved by searching for the pronominal uses of each and one so that the compound forms each other (along with each the other, each an other, each one other, each one the other) and one another (together with one an other, one a other, one and other, one each other, etc.) could be automatically generated. The automatic generation of the discontinuous reciprocals was, however, more complicated insofar as different searches were needed in order to give room to the different prepositions and their variant positions within the prepositional phrase requiring, at least in some cases, more than four different searches. For instance, the construction to each other was expressed with to each other, each to other, each one to other and each to the other, including orthographic variants such as each t' other and each to th' other. In this same vein, the construction to one another required the following searches in the corpus, i.e. to one another, to one an other, one to other and one to the other, setting aside other forms as a result of orthographic variation such as one to'th other, one to t'other, one to ye other and the like.

The $O B C$, on the other hand, has been specifically designed for sociolinguistic research and, apart from POS tags, it is provided with the informants' socio-biographical profile along with the pragmatic characterization of the source (Huber, 2007). The corpus displays a total of 407 proceedings which amount to c. 14 million spoken words (with an average of 750,000 spoken words/decade). The task was more straightforward in this particular case in view of the higher level of orthographic standardization in Late Modern English insofar as it required the generation of the complete concordances of each other and one another both in their fossilized and their discontinuous forms.

Regardless of the corpus, the process was not straightforward and the results had to be manually disambiguated to eliminate the instances not strictly found in a reciprocal function. These two corpora have eventually provided a total of 84,512 instances considering both the fossilized and the discontinuous forms of these reciprocals: 83,817 in EEBOC and 695 in OBC.

\section{Analysis}

\subsection{Origin and grammaticalization of each other}

The reciprocal function of each other can be traced back to Old English in those constructions where the Anglo-Saxon quantifier ælc occurs with the alterity word ōper in neighbouring

12 CLAWS (Constituent Likelihood Automatic Word-tagging System) has been developed at the University Centre for Computer Corpus Research on Language (UCREL) at the University of Lancaster (Garside, 1987: 30-41; Garside and Rayson, 1997: 179-193; Garside and Smith, 1997: 102-121; Kübler and Zinsmeister, 2015: 192). 
positions in statements such as hi cwædon ælc to oprum 'they spoke each to the other' (OE Gospels, Mk, IV, 41). As shown, each was generally the subject and other governed in the accusative, genitive or the dative case by a verb, a preposition or a noun, as in examples (1-2).

(1) Heora pær æ3ðer oðerne ofslo3 (Orosius, II, iii, §2, c. 893).

(2) Us is eallum pearf đæt ure æ⿸厃㔾hwylc oðerne bylde (Battle of Maldon, 234, c. 1000).

A series of morpho-syntactic and semantic changes derived in the development of the quantifier and the alterity word into the fossilized expression each other. The fossilization of each other is dated towards the beginning of the 13th century when the second element already appears inflectionless, as in (3-4). Even though the new form soon adopted the use of prepositions (i.e. to each other, of each other), it was then reluctant to appear in subject positions and today it is still considered a vulgarism occasionally heard (OED s.v. each pron.).

(3) Wende æche oðer pat hit weoren heore broðer (La3amon's Brut, MS Clg A.9, C. 1200).

(4) Dæt æch oper helpe pæt for to done (Proclamation Henry III, Stubbs Sel. Chart. 288, c. 1258).

The origin of this reciprocal, however, is still unresolved. Visser considers its genesis in a reduced clause with two subjects consisting of a subject in the form of a noun or a personal pronoun + verb + each ... other. If each is taken to have a subject role here, the reciprocal meaning of the statement they kissed each other ultimately stemmed from they kissed; each ... other (1963: 445). Haas, in turn, views this process from the discontinuous construction each knight fights the other to the invariable reciprocal expression the knights fight each other as a result of both grammaticalization and lexicalization operating at different points in their development, even though not necessarily dependent upon each other (2010: 65-66; also 2007: 33). Lexicalization, on the one hand, implies the co-occurrence of univerbation and fossilization. Some clear symptoms of this process of fossilization are a) the newly-adopted grammatical positions, not allowed if independently used (i.e. prepositional phrases); b) the loss of morphological information (i.e. the absence of plural marking and the definite article with the alterity word); and c) stress placement (on the second syllable of the unified construction). Grammaticalization, on the other, is attested in view of the different stages of syntactic context expansion. ${ }^{13}$ According to Haas, "the crucial change took place when each other could follow prepositions as a unit”, becoming not only admitted in direct object positions but also in prepositional phrases (2007: 44). The expansion is then observed to adopt additional syntactic contexts, be-

13 The source elements are considered grammatical expressions in view of the grammatical categories to which each and other belong in isolation. In view of the development, the fossilized construction cannot be considered a typical case of grammaticalization to the extent that it has experienced a further degree of grammaticalness, becoming a typical case of syntactic context expansion instead (Haas, 2010: 77). 
coming also possible with genitive constructions as a pre-nominal possessor. Three centuries later, however, this reciprocal experienced a further step in the grammaticalization continuum with the adoption of subject positions in subordinate clauses, the fronted noun phrase in a cleft construction or in a predicative noun phrase following a copular verb (Haas, 2010: 77-78).

The adoption of the new syntactic positions provides crucial information about the chronology of the process of grammaticalization. Even though the first compound units of each other are already attested in the 13th century, it was necessary to wait until the 1540 s for the early instances in prepositional phrases (Raumolin-Brunberg, 1997: 230). The process of syntactic context expansion was not overnight and, when it comes to prepositional phrases, the original discontinuous forms each of other and each with other coexisted for some centuries with the compound forms of each other and with each other. Figure 1 reproduces the distribution of the discontinuous and the compound forms in prepositional phrases in the period 1580-1690 based on the evidence of EEBOC. ${ }^{14}$

\section{FIGURE 1}

Discontinuous and compound forms of each other in prepositional phrases (\%)

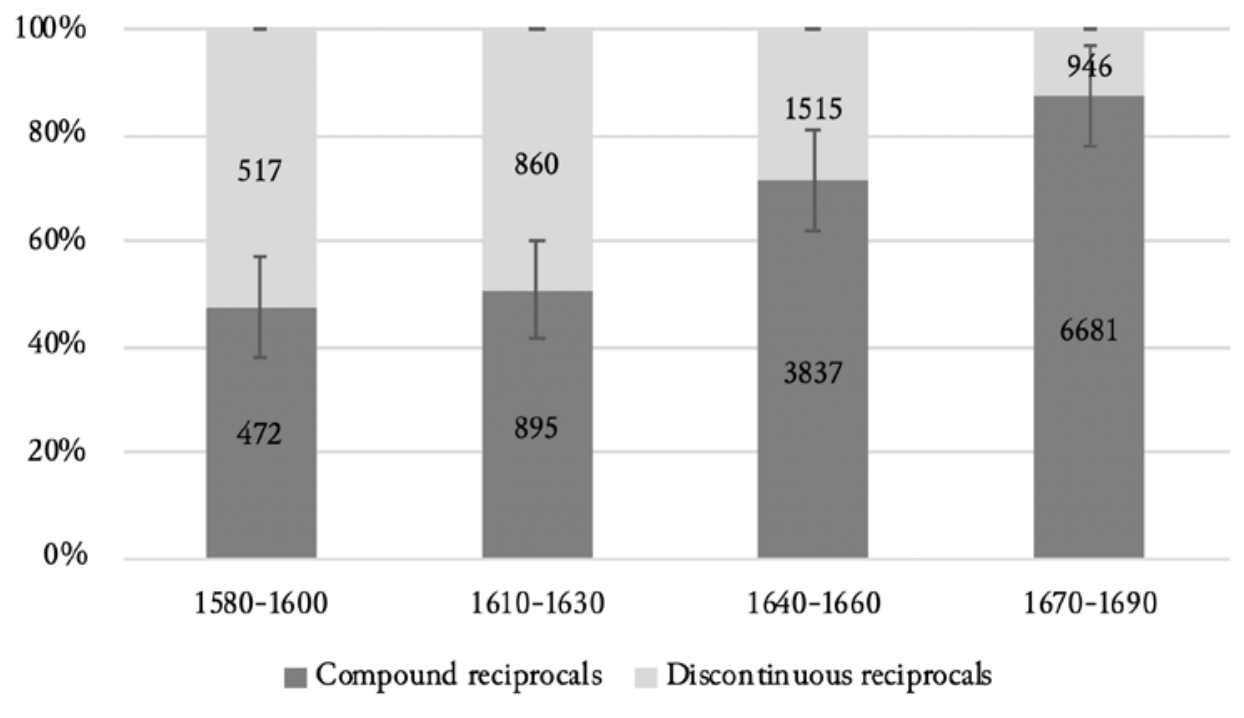

The results confirm that the discontinuous construction still predominates over the compound form until the end of the 16 th century with a rate of $52.27 \%$ and $47.73 \%$, respectively.

14 Figure 1 considers the following prepositional phrases, i.e. against each other vs. each against other, at each other vs. each at other, for each other vs. each for other, from each other vs. each from other, in each other vs. each in other, into each other vs. each into other, of each other vs. each of other, on each other vs. each on other, to each othervs. each to other, towards each other vs. each towards other, unto each othervs. each into other, upon each other vs. each upon other, with each other vs. each with other and without each other vs. each without other. 
Next, the compound form is observed to rise in the period 1610-1630 to such an extent that both forms coexisted with a similar rate during the first quarter of that same century (with a percentage of $49 \%$ and $51 \%$ of the discontinuous and the compound forms, respectively). After this lapse of linguistic competition, there is a substantial rise of the compound form from the $1640 \mathrm{~s}(71.7 \%)$, which coincides with the progressive disappearance of the discontinuous construction (28.3\%). The last period, in turn, corroborates the progressive decline of the discontinuous construction as it is found to decrease to a rate of just $12.4 \%$ in the last quarter of the 17 th century. In this same vein, the error bars in figure 1 reflect that there is a significant difference between the periods 1610-1630 and 1640-1660 inasmuch as the latter presents the grammaticalization and decisive dissemination of the compound form of this reciprocal in the history of English. The chi-square test has been applied to the last two periods (1640-1660 and 1670-1690) and the difference is found to be highly significant ( $\left.X^{2} 516.66, p<0.0001\right)$.

Another issue is whether the fossilization was uniformly achieved irrespective of the preposition. Figure 2 presents the distribution of the compound and discontinuous forms of each other in three high-frequency prepositional phrases, i.e. to each other, from each other and of each other. The compound reciprocals to each other and from each other, on the one hand, follow the general trend according to which the discontinuous forms systematically decline from the 1640 s. The prepositional form of each other, on the other hand, is found to disseminate four decades earlier than the other members of its paradigm. Therefore, the data lead us to state that the phenomenon started at the beginning of that century in combination with the high-frequency preposition of and spread to the other prepositions three decades later.

\section{FIGURE 2}

Distribution of the prepositions to, from and of in their discontinuous and compound forms (n.f.)
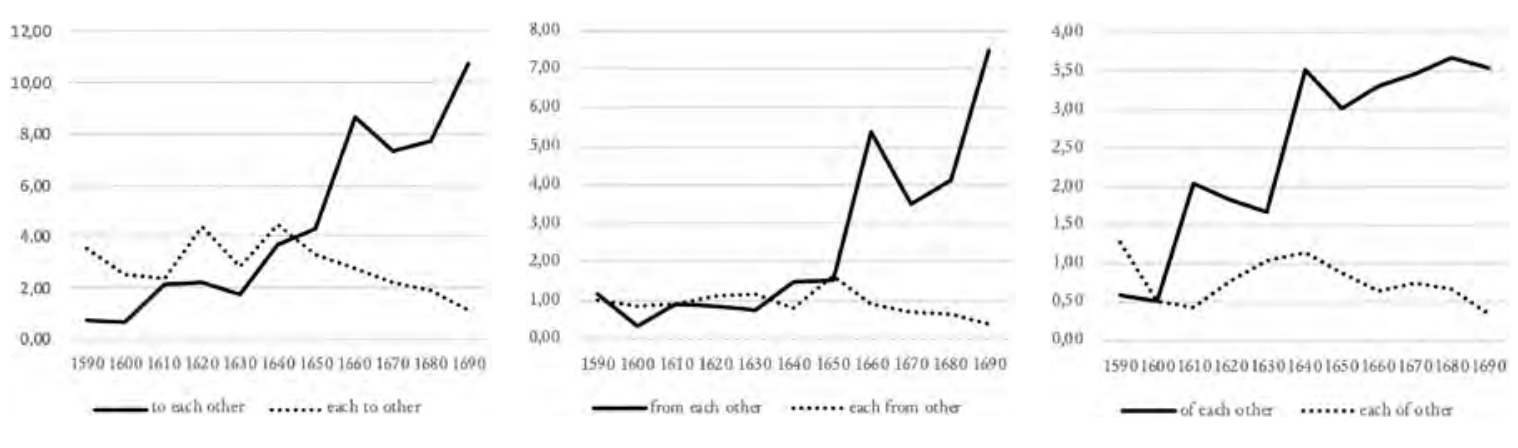

\subsection{Origin and grammaticalization of one another}

The origin of one another is more difficult to assess in the light of the positional restrictions of one in Old and Middle English. Unlike the development of each other, where the quantifier each was susceptible to have post-verbal position as a result of a phenomenon called 'quantifier float', the quantifier one cannot behave as a floating quantifier and, therefore, it 
is not susceptible to adopt post-verbal positions. ${ }^{15}$ The origin, however, must be sought in a different scenario and, according to Plank's account of the formation of bipartite reciprocals in Germanic, the origin of one another should be explained in those contexts in which the quantifier appears post-verbally in combination with the alterity word (Plank, 2008: 360). This is only possible when "the verb does not govern a prepositional complement but rather a direct object, quantifier and alterity word come to stand adjacent to each other and their reanalysis as a single reciprocal expression would be possible" (Haas, 2010: 83). In this fashion, Haas proposes the following development conceived as a three-stage process:

i) The knights hugged; one hugged another

ii) The knights hugged; one $e_{1}$ another

iii) The knights hugged one another

The first example is the earliest stage of the construction with two clauses, the first implying the reciprocal meaning of the utterance and the second repeats the verb with one and another acting as the subject and object, respectively. In the second stage the verb of the second clause is omitted, the default option in such cases. The third, in turn, consists in the reanalysis of one another as a single reciprocal construction functioning as the direct object of the verb (Haas, 2010: 84).

The reciprocal function of one another is a Late Middle English innovation consisting of (the) one + (the) (an)other, where the first element is also the grammatical subject and the second the object (Haas, 2010: 63-68). The first recorded instance dates back to 1340 with the construction one the other, as in example (5) (OED s.v. one pron.; MED s.v. one pron. 3). Following the line initiated by its precursor each other, it progressively became a kind of reciprocal pronoun accepting the objective and possessive cases as in examples (6-7), ${ }^{16}$ whilst the nominative case is again avoided as vulgar (OED s.v. one pron.).

(5) We ssolle ech louye oper, and nazt hatie, ne harmi mid wrong on pe oper (Ayenbite of Inwyt, 115, C. 1340).

(6) [...] for as prudent plato / playne doth recorde and wryte one man for another / is borne euery hour and tyme to be redy / refusynge no labour to confort / to couseyll / and socour

15 According to Rissanen, one sporadically adopts a post-verbal position for the expression of heightened emphasis (1967: 312) suggesting this as the origin of the reciprocal use of one. Haas, however, contradicts this opinion in view of the impossibility that such an emphatic use of one, where one exclusive individual is involved, may have been the source of the present-day English reciprocal (2010: 82)

16 The construction with each other is largely favoured over one another for the expression of the possessive case (OED s.v. another pron. 7). 
one another both true / glad / and redy / as brother vnto brother (Dominicus Mancinus, The Mirror of Good Manners, 1518).

(7) Prolepsis, is a brief expression of things; as, two eagles flew, this from the east, that from the west: the people live, som in want, som in delights: [...] bear yee one another's burdens: let both of us take an equal share (Charles Hoole, The Latine Grammar Fitted for the Use of Schools, 1651).

Even though some sporadic examples of the fossilized form one another are already attested in the early 16th century, it was not until the second quarter of that century when the construction gained more substantial ground, coexisting for some time with the discontinuous forms of this reciprocal, as shown in (8). It is difficult, however, to trace the univerbation of the construction if the reciprocal is in the objective case in view of the fact that the alterity word may at times appear without its premodifier, as in example (9).

(8) Blessyd be the mercyful: for they shal haue mercy: after in the same letter sayth he:yf we pardone not that one the other/god shal not pardone vs (William Caxton, The Royal Book, 1486).

(9) [...] then shall both man and wife helpe the one other for to get theire expences (Henricus Bomelius, The Summe of the Holye Scripture, 1529).

The actual univerbation of the construction may then be explored attending to the placement of the preposition, which initially modifies the alterity word and later comes to head the fossilized expression, as in (10-11).

(10) they said oon to an other that they durste not come and assaylle hem (William Caxton, The Recuyell of the Historyes of Troye, 1474).

(11) [...] and aduising it for the best, neuer to make priuy to one another of our loues: both of vs perfourmed maruelous seates in this tourney to incline this Princesse to loue vs the more (Anthony Munday, The First Book of Primaleon, 1595).

Figure 3 therefore presents the distribution of the compound and discontinuous forms of one another in the period 1580-1690 to ascertain a likely date for the univerbation of the reciprocal function of one another. ${ }^{17}$ As in the case of each other, the development is represented

17 Figure 3 considers the following prepositional variants, i.e. against one another vs. one against (the) other/another, at one another vs. one at (the) other/another, for one another vs. one for (the) other/another, in one another vs. one in (the) other/another, into one another vs. one into (the) other/another; of one another vs. one of (the) other/another, on one another vs. one on (the) other/ another, to one another vs. one to (the) other/another; with one another vs. one with (the) other/ another and without one another vs. one without (the) other/another, including the different orthographic representations of another (an other, ye other, t'other, etc.). 
in terms of four different sub-periods of three decades each, 1580-1600, 1610-1630, 1640-1660 and 1670-1690.

\section{FIGURE 3}

Discontinuous and compound forms of one another in prepositional phrases (\%)

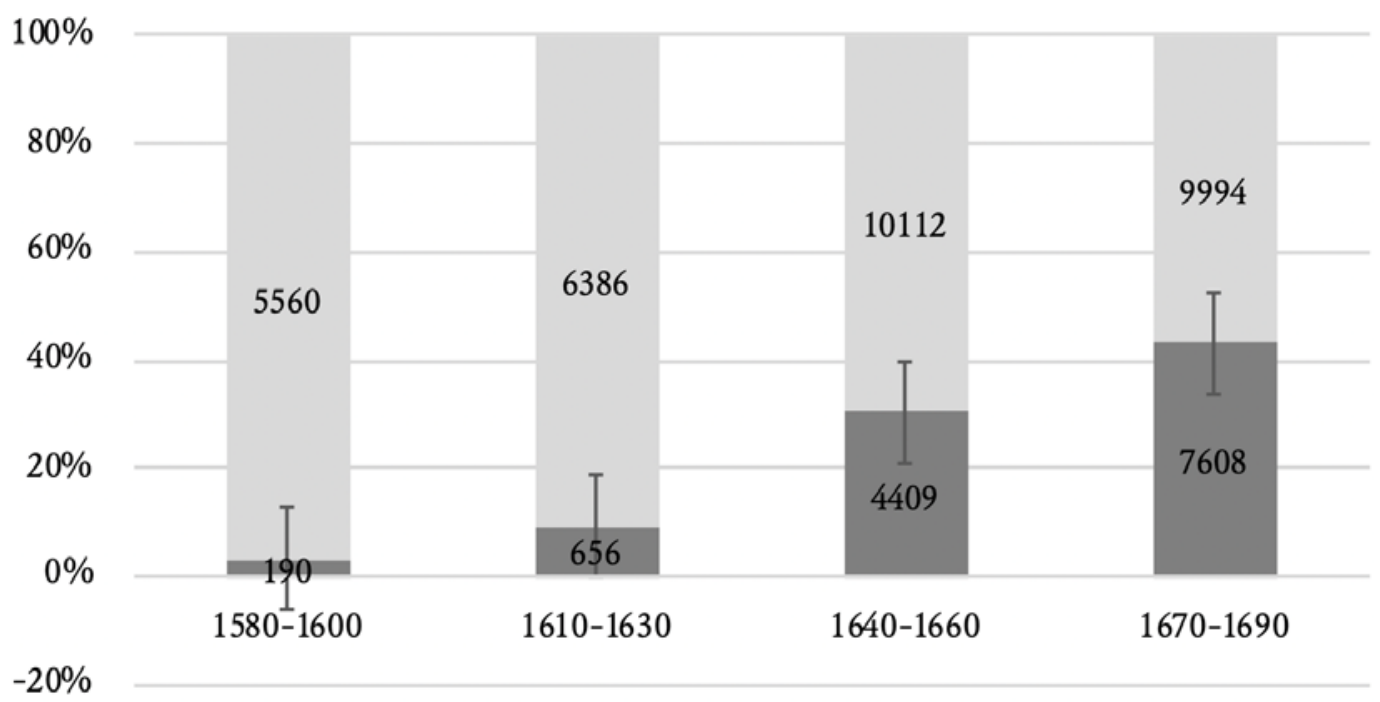

$-20 \%$

\section{Compound reciprocals $\square$ Discontinuous reciprocals}

Unlike the diffusion of each other, in itself an Early Modern English innovation, the univerbation of one another is observed to occur at a much slower pace, perhaps as a result of its more constrained distribution. Notwithstanding the general preference for the discontinuous form throughout the whole Early Modern English period, the data in figure 3 lead us to ascertain the period $1640-1660$ as a crucial period in the development of the compound form of one another. While the first two sub-periods present a similar distribution of both constructions with the overlapping of the error bars, the error bar in the period 1640-1660 reflects that there is a significant difference between the second and the third sub-period. For accuracy, the chi-square test has been applied to the last two periods (1640-1660 and 1670-1690) confirming that the difference is found to be very significant $\left(X^{2} 561.4, p<0.0001\right)$. The rise of the fossilized construction also coincides with the progressive decline of the discontinuous form in the last quarter of the 17 th century with a distribution of $43.23 \%$ and $56.77 \%$ in the period $1670-1690$. Unfortunately, however, the chronology of EEBOC does not allow us to see the wood for the trees in terms of their subsequent development, but the positive attitude towards the compound form, together with the parallel trajectory of each other, lead us to propose the early 18th century, most probably not later than 1710, as the likely date for the actual univerbation of the reciprocal function of one another. 


\subsection{Each other vs. one another}

This section investigates the chronological development of both reciprocals over time. To my knowledge, Raumolin-Brunberg's is the only diachronic study of the phenomenon in early English in the light of the evidence provided by the Helsinki Corpus (HC) in the period 1500-1710. Figure 4 presents her results, where she concludes that one another is the most frequent form until the last sub-period (1640-1710), when each other begins to rise becoming slightly more common. The variant form the one the other remains with a constrained distribution throughout the whole Early Modern English period (1997: 232).

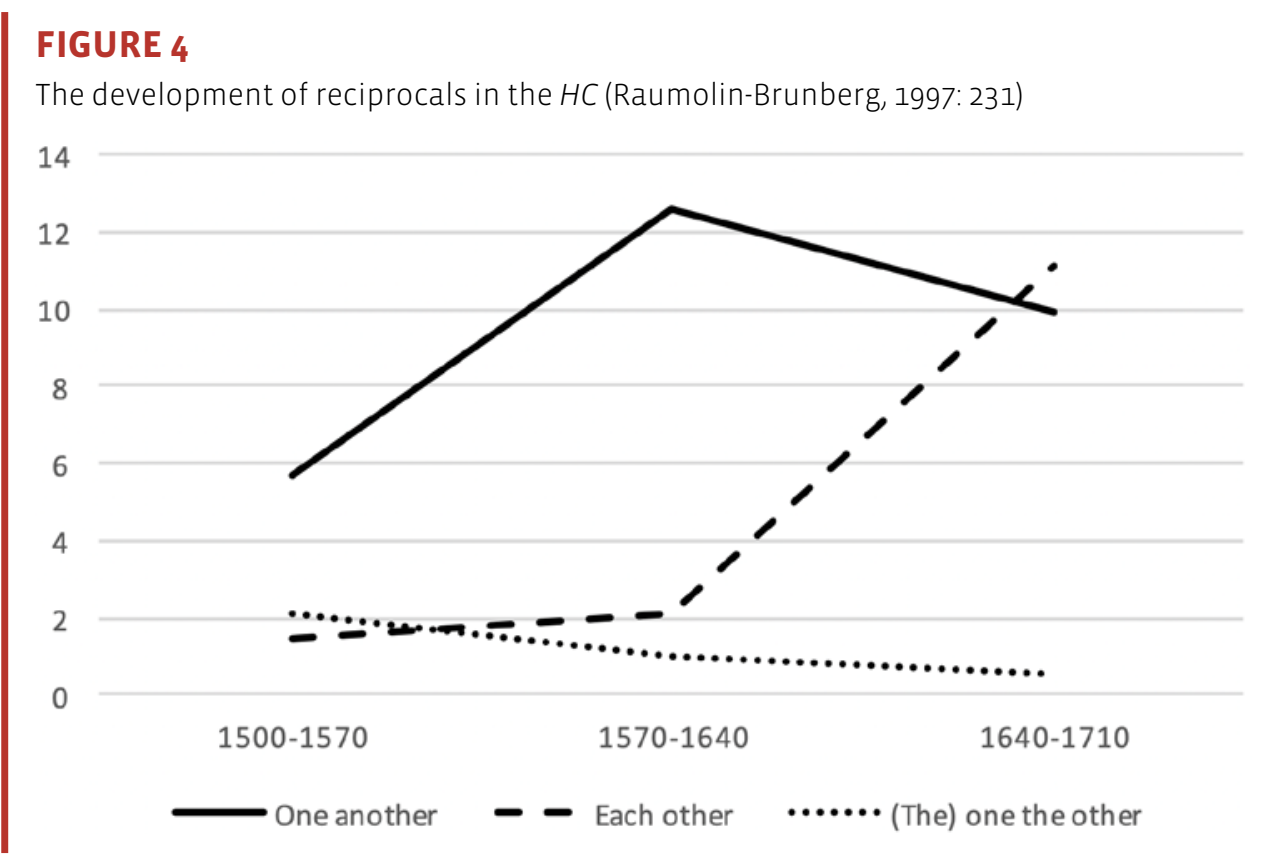

The size of the $H C$, however, turns it into a diagnostic corpus providing just general information about the distribution of particular linguistic forms in the history of English. The results obtained from this corpus need to be further supplemented and checked against other focused historical corpora. In addition to this, Raumolin-Brunberg's study offers a partial account of the phenomenon with the development of the compound forms each other, one another and the one the other, omitting any reference to other compound forms (i.e. each the other, each one the other, one and other) and, more importantly, to reciprocals in prepositional functions, both with each (i.e. each to the other, each for the other, each with the other, etc.) and one (i.e. one to the other, one for the other, one with an other, etc.), which could have shed some more light on the development of these reciprocals in early English. For this reason, the present study takes Raumolin-Brunberg's study as a starting point in order to validate her findings with the use of the $H C$ offering a more comprehensive account of their development in the modern period. 
Figure 5 reproduces the distribution of each other, one another and the one the other in EEBOC in the historical period $1480-1650 .{ }^{18}$ On the one hand, the results show that both reciprocals gain substantial ground over time. This increase is surely associated with the general collapse of the Middle English system for the expression of reciprocity, expressed with a wide variety of linguistic forms, the list including each/every ... other, one ... other, either ... other (Mustanoja, 1960: 153-154), all of which characterised by the discontinuity of the subject and the object. The divided subject use became progressively obsolete from the beginning of the 16th century and compound units started to develop for these purposes. On the other hand, the data also show that one another is outstandingly preferred over each other in the whole period. In the 1600 s, there is a distribution of 47.39 and 13.85 occurrences (n.f. per million words) of one another and each other, respectively. In the 1650s, however, the difference increases insofar as the former already doubles the latter with 78.55 and 32.26 occurrences, respectively. The difference remains at the end of the period as there are 107.16 occurrences of one another and just 51.84 occurrences of each other in the last decade of the corpus. The one the other, in turn, remains as a residual form for the expression of reciprocity in the period with a timid rise after 1560 .

In the light of these data, the diffusion of each other is then found not to respond to an Early Modern English impulse, as hitherto postulated by Raumolin-Brunberg in her analysis of the $H C$. The issue is then when and why each other eventually outnumbered one another in the history of English. Figure 6 reproduces the distribution of both reciprocals in the Late Modern English period based on the evidence provided by the $O B C$ and, for comparison, the figures have been conveniently normalized (per million words). For the sake of a diachronic analysis, the corpus material has been classified into four fifty-year sub-periods based on the year of the proceedings. Setting aside the disappearance of the one the other, the results show the progressive decline of one another coinciding with the diffusion of each other for the expression of reciprocity. Even though both forms are equally distributed in the period

18 The results incorporate the occurrences of the different orthographic realizations of these variants. The occurrence of each other includes forms such as each other, each an other, each one the other, each the other, each t'other and each o other, some of them residual in our data. One another, in turn, incorporates one another, one an other, one and other, one each other, one a other and one o other. In the same vein, the one the other agglutinates variant forms like the one the other, (the) one and the other, one th' other, one t' other, one and t'other, etc. For accuracy, the classification of these orthographical variants has been carried out considering the actual expression of the quantifier and the alterity word, a fact which explains why, for instance, variants such as each an other and each the other have been safely ascribed to the reciprocal each other. In the light of this decision, the variant form each one the other could be tentatively ascribed either to each other or to the one the other. In the present study it has been considered as a variant form of each other in view of the presence of each and other in the construction. This form, however, presents a very low occurrence in the corpus (with just 15 tokens) and the ascription of this orthographical variant to either group would not distort the tendencies shown in figure 5. 
1750-1799, each other already outnumbers one another at the beginning of the 19th century, with 32.33 and 15.25 occurrences, respectively. The difference becomes more prominent in the second half of that century when the former manages to double the latter with 43.08 and 22.67 occurrences, respectively.

\section{FIGURE 5}

The development of reciprocals in the EEBOC (n.f.)

120

100

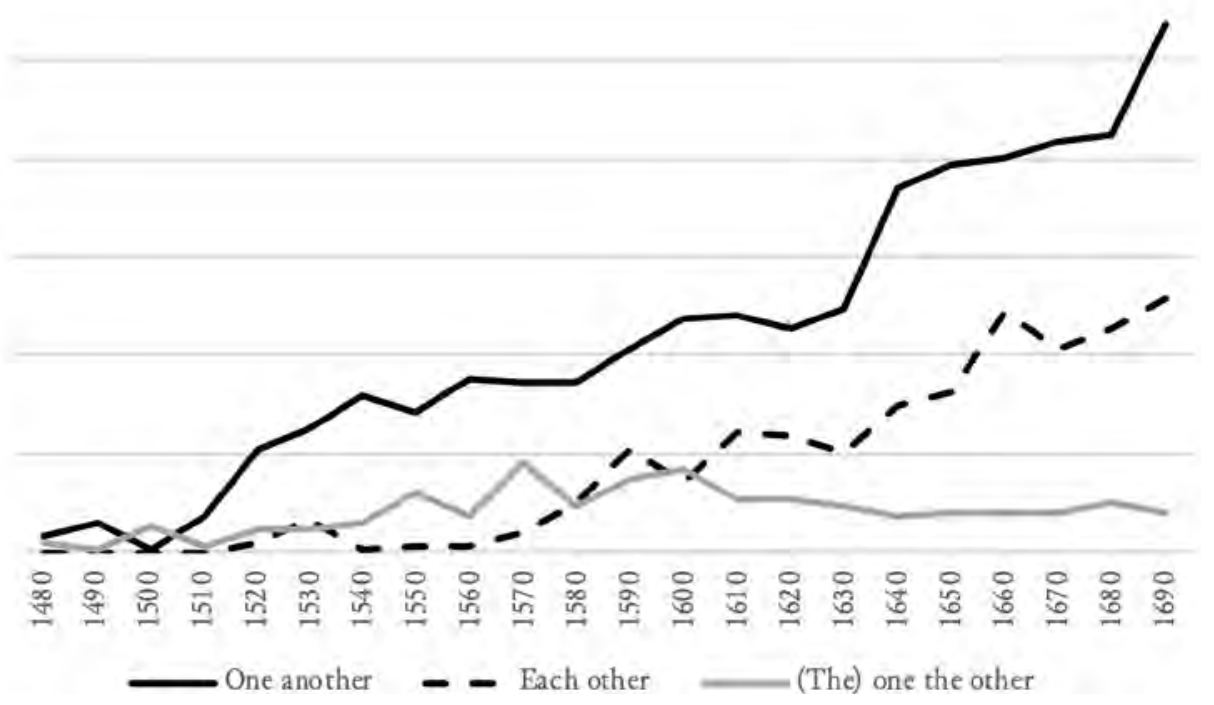

FIGURE 6

The development of reciprocals in the $O B C$ (n.f.)

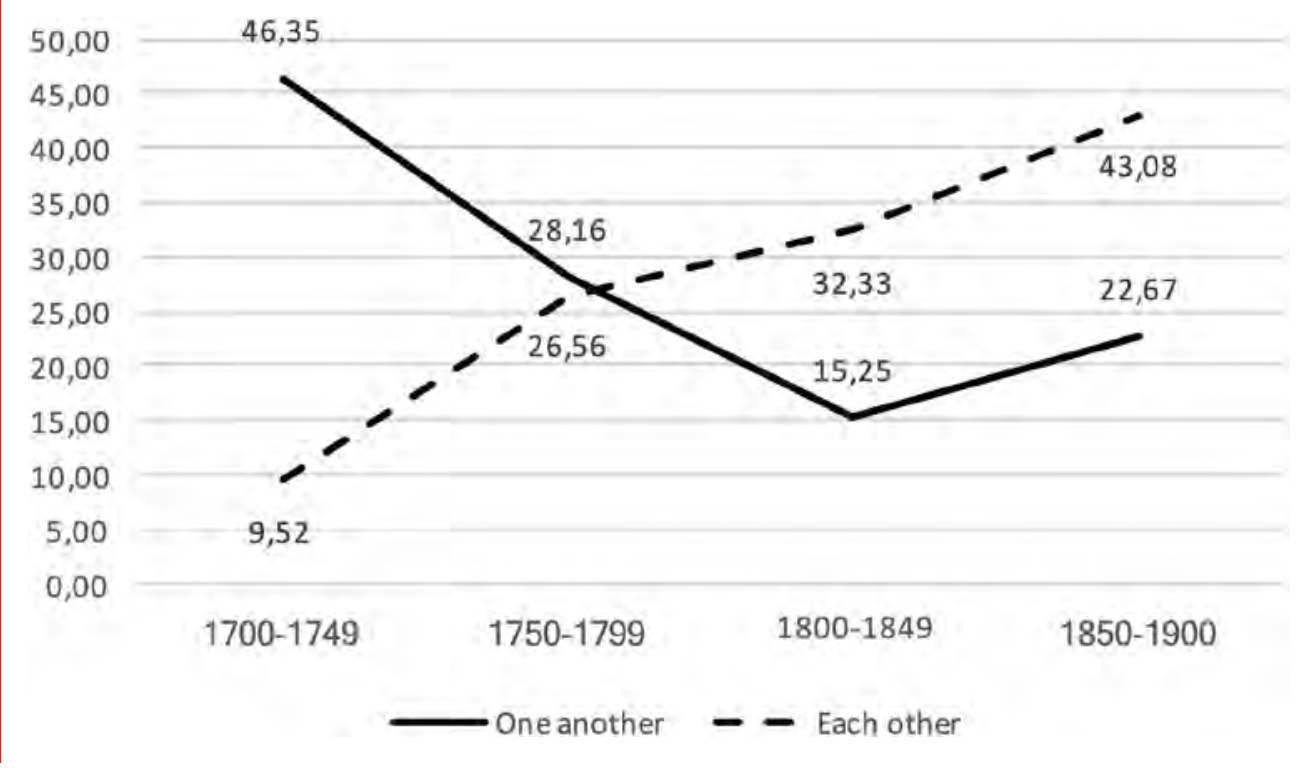


The development of each other could be tentatively described in terms of the traditional S-shaped curve type diffusion (Labov, 1994: 65-66), according to which there is slow spread in the initial stages of a change, followed by a period of rapid acceleration, and the trajectory of the diffusion eventually slows down before it is completed, with a transition from innovation to propagation (Denison, 2004: 58). ${ }^{19}$ These ongoing changes, in Labov's terms, can be further divided into five stages covering the areas of the S-curve, i.e. incipient, new and vigorous, mid-range, nearly completed and completed phases (1994: 79-83). While in the period 17001749 the diffusion of each other is still incipient, the second half of the 18th century shows how this reciprocal rises considerably becoming new and vigorous. The early 19th century, however, just shows a slight increase in the frequency of the construction, then confirming that it has already reached the phase of mid-range diffusion. In the period 1850-1900, the frequency of each other notably increases, especially if compared with the previous sub-period, which tentatively corroborates that the diffusion is nearly completed. The completed phase, however, takes place in the 2oth century, where the frequency of the construction acquires a stable distribution. The S-curved diffusion of each other stands out as a typical case of linguistic competition to such an extent that it simultaneously derives in the eventual decline of one another. Interestingly enough, figure 6 shows how both reciprocals are observed to have a similar distribution in the period 1750-1799, when each other is in the new and vigorous phase, whilst in the following sub-period it has significantly outnumbered one another after the completion of the mid-range diffusion phase.

The reason for the rise of each other can be tentatively explained from a sociolinguistic perspective. The $O B C$ is annotated to contain the sociohistorical background of the informants, including variables such as age, gender, occupation and social class according to the Historical International Standard Classification of Occupations, which ranks Late Modern English society in terms of a condensed 7-class scheme, as shown in figure 7. This scheme ranges from higher managers and professionals to the bottom of the social ladder, consisting of lower-skilled or unskilled workers.

Figure 7 reproduces the distribution of each other and one another in the light of this sociohistorical classification to evaluate the influence of the informants' sociolinguistic profile in the development of both reciprocals. Even though both present a similar distribution among the top members of the high class (i.e. high managers and professionals), the definite impulse for each other stems from other groups of the high-class members, consisting of lower managers and professionals, clerical and sales personnel (where each other more than doubles

19 Despite the recurrent use of the traditional S-shaped curve in the diffusion of linguistic changes, Denison warns that "the S-curve is neither as simple nor as uniform a phenomenon as it is sometimes assumed [...] the S-curve should not be seized on too readily as the general shape of language change" (Denison, 2004: 68; also Wardhaugh, 2010: 222). 


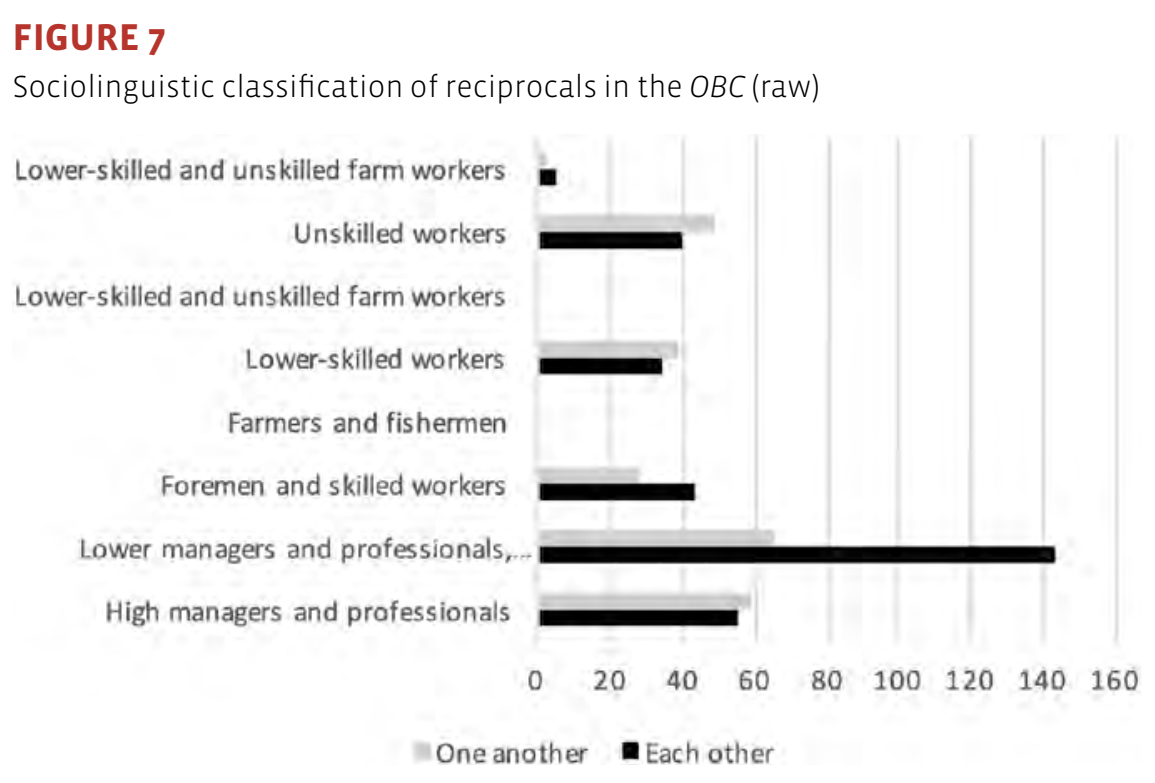

the occurrence of one another) followed by the group of foremen and skilled workers. In contrast, one another still outnumbers each other in the rest of the social groups at the bottom of the scheme, both among the members of lower-skilled and the unskilled workers. In view of this, the phenomenon may be considered to be a change from above. Unlike changes from below, which remain below the level of social awareness, it is a change above the level of the speaker's conscious awareness and, as such, they "are introduced by the dominant social class, often with full public awareness", primarily in careful speech (Labov, 1994: 78; also MacMahon, 1994: 244; Nevalainen, 1996: 15).

The next issue is whether these reciprocals developed a particular linguistic configuration after the general adoption of each other for the expression of reciprocity. These two forms have coexisted for more than five centuries in the history of English standing out as a typical example of linguistic forms in competition and, more importantly, they have remained impervious to any kind of linguistic change or the eventual disappearance of one of them (Kahlas-Tarkka, 2004: 132). Prescriptive grammars have traditionally argued for the use of the concord rule according to which each other and one another refer to two or more than two entities, respectively. Today this postulate is no longer a matter of contention insofar as both forms are elsewhere considered as compatible. The period 1750-1800, when a number of these grammars started to proliferate (Locher, 2008: 129-130), is then crucial to evaluate whether this prescriptive prerogative derives from actual English usage or it was simply a matter of invention. The $O B C$ provides us with 106 and 107 instances of each other and one another in the period 1750-1800, which have been accordingly classified in terms of this prescriptive concord rule. Figure 8 shows the distribution of the reciprocals in terms of their implicit reference distinguishing whether they refer to two or to more than two entities. In some cases, 
the agreement is expressed by means of the pronominals we and they and these examples have been considered as ambiguous in view of the impossibility to discern the number of participants involved in the utterance.

\section{FIGURE 8}

Classification of reciprocals in terms of the participants involved 1750-1800 (raw and \%)

Each other

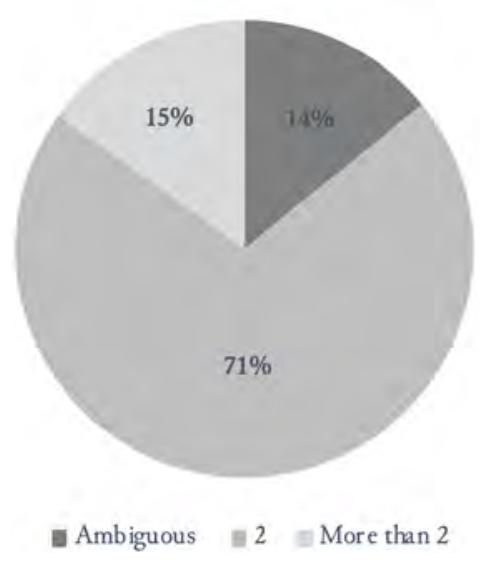

One another

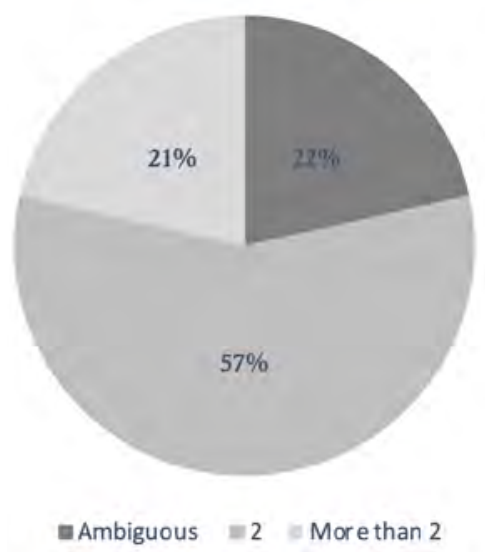

Each other presents a rate of $70.7 \%$ and $\mathbf{1 5 . 0 9 \%}$ to refer to two and more than two entities, respectively. One another, in turn, shows the same state of affairs where the binary reference seems to be the rule rather than an exception with $57 \%$ of the instances, as shown in examples (12-13).

(12) I live just by Mr. Murray, I heard him and the deceased scolding at one another, but did not see Murray do any thing to him (OBC, 1757).

(13) she went to bed about half an hour after me. I believe Mr. Lackey's man and she went up soon after one another (OBC, 1757).

The results tentatively come to prove that the prescriptive tenet was entirely based on unfounded premises. These kinds of misconceptions were commonplace in many 18th-century grammar books, often due to erroneous observation, others to the influence of Latin grammar, and others to the fact that English grammar was often elaborated by Dutch and German scholars (Erades, 1956: 119-148). This prerogative, in my opinion, was surely the result of an erroneous observation stemming from the higher frequency of each other in the language and its tendency to adopt a binary concord rule. Unfortunately, the problem is that some of these false tenets have been taken for granted by the subsequent generations of grammarians, who have indirectly contributed to their preservation even in some grammars and usage books today. 


\section{Conclusions}

The present paper is concerned with the expression of reciprocity in early English, paying special attention to the origin, grammaticalization and univerbation of the reciprocals each other and one another in the period 1470-1913. The study is based on the complete set of reciprocal constructions, either in their fossilized or discontinuous forms, in EEBOC and $O B C$, which have provided us with sufficient data for the analysis of the phenomenon with a total of 83,817 instances in Early Modern English and other 695 instances in Late Modern English. The main conclusions are the following.

The first part of the study is concerned with the configuration of each other as a reciprocal in the history of English. It originally stems from the Old English construction in which the quantifier ælc occurs with the alterity word ōper in neighbouring positions. A process of grammaticalization and lexicalization turned the discontinuous form into a fossilized expression in the first half of the 13th century. The process, however, was not straightforward and the survival of the discontinuous construction until the 18th century gives evidence of the competition of the two forms of this reciprocal until the eventual grammaticalization of the compound form in the 17th century. Based on the evidence of the prepositional uses of this reciprocal, the study concludes that the univerbation of each other is in itself an Early Modern English phenomenon configuring the 1640 s as the crucial decade in which the fossilised expression gained ground to the detriment of the discontinuous form. The process, however, did not disseminate uniformly as the compound construction of each other is found to pioneer the process already in the 1600s, a few decades before the other prepositions.

The second part, in turn, explores the emergence of one another as a reciprocal in English. Developed originally from the Middle English construction (the) one + (the) (an)other, the early instances of this reciprocal in its present-day English form date from the first half of the 14th century and, as with each other, the fossilized and the discontinuous forms coexisted for more than three centuries in the history of English. Even though the study confirms that there was a significant rise of the compound form of one another from the $1640 \mathrm{~s}$ and that both forms coexisted throughout that same century, the actual univerbation of one another was not initiated until the 1690s, perhaps under the shelter of the parallel trajectory of each other six decades earlier.

The third part examines the quantitative dimension of both reciprocals over time. As far as Early Modern English is concerned, one another significantly outnumbers each other throughout the whole period, thus contradicting some earlier accounts which postulated the rise of each other in the second half of the 17th century (Raumolin-Brunberg, 1997: 231). The diffusion of each other in our data is a Late Modern English impulse from the beginning of the 19th century, coinciding with a substantial decline of one another. The phenomenon responds to a sociolinguistic motivation with the pattern of a typical change from above according to which the innovation spreads under the shelter of the higher classes of society 
and, in the particular case at hand, as a result of the impulse of lower managers and professionals, clerical and sales personnel.

Finally, the study has also surveyed the linguistic configuration of these reciprocals in the second half of the 18th century to evaluate whether there is any rationale behind the prescriptive concord rule. Our data confirm that this prescriptive tenet is entirely based on unfounded premises, surely as a result of an erroneous observation stemming from the higher frequency of each other in the language and the tendency to adopt a binary concord rule. It is significant, however, that false tenets like this one have been taken for granted by the subsequent generations of grammarians, who have contributed to their preservation in some contemporary grammars and usage books.

\section{References}

Angus, William, 1800: An epitome of English grammar containing a brief explication of the parts of speech, phrases for parsing, rules of syntax, violation of the rules of syntax, improprieties in the choice of words; [...] calculated for the use of schools, Glasgow.

BAKER, Robert, 1779: Remarks on the English language, in the manner of those of Vaugelas on the French; being a detection of many improper expressions used in conversation, and of many others to be found in authors, London: Etheringtons Press.

BERESFORD, Michael, 1997: Modern English. A user's guide to grammar and style, London: Duckworth.

Biber, Doublas, Stig Johansson, Geoffrey Leech, Susan Conrad and Edward Finegan, 1999: Longman grammar of spoken and written English, London: Longman.

Bolinger, Dwight, 1990: "Re-marking the English reciprocal: commutation versus mutuality" in Jerold A. Edmondson, Crawford Feagin and Peter Mülhäusler (eds.): Development and diversity: language variation across space and time, Dallas: Summer Institute of Linguistics and University of Texas at Arlington, 265-272.

BRown, Goold, 1851: The grammar of English grammars, with an introduction historical and critical, New York: Samuel and William Wood.

CAJKA, Karen, 2008: "Eighteenth-century teacher-grammarians and the education of 'proper' women" in Ingrid TIEKEn-Boon van Ostade (ed.): Grammars, grammarians and grammar-writing in eighteenth-century England, Berlin: Mouton de Gruyter, 191-222.

ChURCHILL, Thomas O., 1823: A new grammar of the English language; including the fundamental principles of etymology, syntax, and prosody, London: W. Simpkin and R. Marshall. 
Dalrymple, Mary, Makoto Kanazawa, Yookyung Kim, Sam Mchombo and Stanley Peters, 1998: "Reciprocal expressions and the concept of reciprocity", Linguistics and Philosophy 21 (2), 159-210.

Denison, David, 2004: "Log(ist)ic and simplistic s-curves" in Raymond Hickey (ed.): Motives for language change, Cambridge: Cambridge University Press, 54-70.

Erades, P. A., 1950: "Points of modern English syntax 12", English Studies 31, 153-155.

Erades, P. A., 1956: "Fantomen in de Engelse grammatica" in P. Erades, K. Heeroma, C. B. van HaerinGen, C. Soeteman and L. Geschiere (eds.): Algemene aspecten van de grote cultuurtalen, Den Haag: Servire, 119-148.

Fowlen, Henry W., 1968: A dictionary of modern English usage, Oxford: Clarendon Press.

GaRDINER, Jane, 1799: The young ladies' English grammar; adapted to the different classes of learners with an appendix, or abbreviation of the grammar, York: Thomas Wilson and Robert Spence.

Garside, Roger, 1987: "The CLAWS word-tagging system" in Roger Garside, Geoffrey Leech and Geoffrey SAMPSon (eds.): The computational analysis of English: a corpus-based approach, London: Longman, 30-41.

Garside, Roger, and Paul RaYson, 1997: "Higher-level annotation tools" in Roger GarSIDE, Geoffrey LeEch and Antony McEnery (eds.): Corpus annotation: linguistic information from computer text corpora, London: Longman, 179-193.

GARSIDE, Roger, and Nicholas SMITH, 1997: "A hybrid grammatical tagger: CLAWS4" in Roger GaRSIDE, Geoffrey LeECH and Antony McEnery (eds.): Corpus annotation: linguistic information from computer text corpora, London: Longman, 102-121.

GILMAN, E. Ward (ed.), 1989: Webster's dictionary of English usage, Springfield, MA: Merriam-Webster Inc.

Greenbaum, Sidney, and Janet Whitcut, 1988: Longman guide to English usage, London: Longman.

Gutschow, Harald, 1960: "Deskriptive und prescriptive Grammatik”, Praxis 7, 32-34.

HAAS, Florian, 2007: "The development of English each other: grammaticalization, lexicalization, or both?”, English Language and Linguistics 11.1, 31-50.

HAAs, Florian, 2010: Reciprocity in English. Historical development and synchronic structure, London: Routledge.

Huber, Magnus, 2007: “The Old Bailey Proceedings, 1674-1834. Evaluating and annotating a corpus of 18th- and 19th-century spoken English" in Anneli Meurman-Solin and Arja Nurmi (eds.): 
Annotating variation and change, Helsinki: VARIENG [http://www.helsinki.fi/varieng/series/ volumes/01/huber, accessed June 23, 2018].

JøRGENSEN, Erik, 1988: “Each other - one another”, English Studies 69 (4), 355-357.

KAHLAS-TARKKA, Leena, 2004: "A ‘two-way relationship in English' revisited: on reciprocal expressions in early English, with a digression into modern English uses", Studia Anglica Posnanien$\operatorname{sia} 40,121-134$.

KJELLmer, Göran, 1982: "Each other and one another: On the Use of the English Reciprocal Pronouns", English Studies 63 (3), 231-254.

Kübler, Sandra, and Heike ZInsmeIster, 2015: Corpus linguistics and linguistically annotated corpora, London: Bloomsbury.

Kruisinga, Etsko, 1938: "Each other und one another", Anglia 49, 85-87.

Labov, William, 1994: Principles of linguistic change. Vol. 1: Internal factors, Oxford: Basil Blackwell.

LOCHeR, Miriam A., 2008: "The rise of prescriptive grammars on English in the 18th century" in Miriam A. Locher and Jürg StrÄssler (eds.): Standards and norms in the English language, Berlin: Mouton de Gruyter, 127-147.

MARSH, Thomas, 1862: Grammar of the English language, including its history and development, with all the latest improvements, London: Simpkin Marshall \& Co.

McMahon, April, 1994: Understanding language change, Cambridge: Cambridge University Press.

Mustanoja, Tauno, 1960: A Middle English syntax. Part I: parts of speech, Helsinki: Société Néophilologique.

Nevalainen, Terttu, 1996: "Historical sociolinguistics" in Terttu Nevalainen and Helena RaumoLIN-Brunberg (eds.): Sociolinguistics and language history. Studies based on the Corpus of Early English Correspondence, Amsterdam: Rodopi, 11-38.

Partridge, Eric, 1947: Usage and abusage. A guide to good English, London: Penguin.

Pink, M. Alderton, 1928: A dictionary of correct English. A manual of information and advice concerning grammar, idiom, use of words, points of style, punctuation, spelling, and other practical matters, London: Sir Isaac Pitman \& Sons. 
PLANK, Frans, 2008: "Thoughts on the origin, progress, and pro status of reciprocal forms in Germanic, occasioned by those of Bavarian" in Ekkehard KöNIG and Volker GAST (eds.): Reciprocity and reflexivity: theoretical and typological explorations, Berlin: Mouton de Gruyter, 347-373.

Potter, Simon, 1953: “The expression of reciprocity”, English Studies 34, 252-257.

Quirk, Randolph, Sidney Greenbaum, Geoffrey Leech and Jan Svartvik, 1985: A comprehensive grammar of the English language, London and New York: Longman.

Raumolin-Brunberg, Helena, 1997: “Reciprocal pronouns: from discontinuity to unity”, Studia Anglica Posnaniensia 31, 227-236.

Rissanen, Matti, 1967: The uses of one in Old and early Middle English, Hrlsinki: Société Néophilologique.

StANIFORD, Daniel, 1800 [1797]: A short but comprehensive grammar, rendered simple and easy by familiar questions and answers, Charlestown.

StuURman, Frits, 1987: "Each other - one another: "there will always prove to be a difference'”, English Studies 68 (4), 353-360.

StuURman, Frits, 1989: “Each other - one another: to reciprocate”, English Studies 70 (4), 356-359.

Sullivan, Robert, 1855: An attempt to simplify English grammar; with observations of the method of teaching it, Dublin: Marcus and John Sullivan.

Ussher, George Neville, 1775: The elements of English grammar, Menston: The Scolar Press Limited.

TodD, Loreto, and Ian Hancock, 1986: International English usage, London: Crook Helm.

VISSER, Frederick T., 1963: An historical syntax of the English language, part 1: syntactical units with one verb, Leiden: Brill.

Wardhaugh, Ronald, 2010: An introduction to sociolinguistics, Oxford: Wiley Blackwell.

XIAO, Richard, 2008: "Well-known and influential corpora” in Anke LüDELING and Merja KYTö (eds.): Corpus linguistics. An international handbook, Berlin: Mouton de Gruyter, 383-456. 